\title{
BM] Global Health Lessons from the first 6 years of an intervention-based field epidemiology training programme in Papua New Guinea, 2013-2018
}

\author{
Barry Ropa, ${ }^{1}$ James Flint (D) ${ }^{2}$ Michael O'Reilly, ${ }^{3}$ Boris Igor Pavlin, ${ }^{4}$ \\ Rosheila Dagina, ${ }^{1}$ Bethseba Peni, ${ }^{5}$ Mathias Bauri, ${ }^{1}$ Alois Pukienei, ${ }^{6}$ Tony Merritt, ${ }^{2}$ \\ Steven Terrell-Perica, ${ }^{3}$ Abel Yamba, ${ }^{3}$ Dimitri Prybylski, ${ }^{3}$ Julie Collins, ${ }^{2}$ \\ David N Durrheim, ${ }^{2}$ Alden Henderson, ${ }^{3}$ Sibauk Bieb ${ }^{1}$
}

To cite: Ropa B, Flint J, 0 'Reilly M, et al. Lessons from the first 6 years of an intervention-based field epidemiology training programme in Papua New Guinea, 2013-2018. BMJ Global Health 2019;4:e001969. doi:10.1136/ bmjgh-2019-001969

Handling editor Seye Abimbola

Received 7 September 2019 Revised 18 November 2019 Accepted 22 November 2019

Check for updates

C Author(s) (or their employer(s)) 2019. Re-use permitted under CC BY-NC. No commercial re-use. See rights and permissions. Published by BMJ.

For numbered affiliations see end of article.

Correspondence to

Mr James Flint

james.flint@health.nsw.gov.au

\section{ABSTRACT}

Papua New Guinea (PNG) faces a critical shortage of human resources to address pressing public health challenges arising from an increasing burden of communicable and non-communicable diseases. PNG is an independent State in the Pacific and home to 8.2 million people. Resource and infrastructure constraints due to the country's challenging geography have made it difficult and expensive to deliver health services and implement health programmes. The National Department of Health and its partners developed a field epidemiology training programme of Papua New Guinea (FETPNG) to strengthen the country's public health workforce. The training programme covers field epidemiology competencies and includes the design, implementation and evaluation of evidence-based interventions by Fellows. From 2013 to 2018, FETPNG graduated 81 field epidemiologists. Most FETPNG graduates (84\%) were from provincial or district health departments or organisations. Many of their intervention projects resulted in successful public health outcomes with tangible local impacts. Health challenges addressed included reducing the burden of multi-drug resistant-tuberculosis (TB), increasing immunisation coverage, screening and treating HIV/TB patients, and improving reproductive health outcomes. FETPNG Fellows and graduates have also evaluated disease surveillance systems and investigated disease outbreaks. Early and unwavering national ownership of FETPNG created a sustainable programme fitting the needs of this low-resource country. A focus on designing and implementing effective public health interventions not only provides useful skills to Fellows but also contributes to real-time, tangible and meaningful improvements in the health of the population. The graduates of FETPNG now provide a critical mass of public health practitioners across the country. Their skills in responding to outbreaks and public health emergencies, in collecting, analysing and interpreting data, and in designing, implementing and evaluating public health interventions continues to advance public health in PNG.

\section{INTRODUCTION}

The field epidemiology training programme of Papua New Guinea (FETPNG) is a
Summary box

- Early and unwavering national ownership of field epidemiology training programme of Papua New Guinea (FETPNG) has created a sustainable programme that fits the needs of this low-resource setting.

- A focus on designing and implementing effective public health interventions not only provides useful skills to fellows but contributes to real-time, tangible and meaningful improvements in the health of the population.

- The network created by FETPNG has supported the practice of public health in PNG by providing a critical mass of public health practitioners who share a common epidemiological approach, and are skilled in collecting and analysing data, designing and implementing interventions, conducting monitoring and evaluation, and responding to emergencies.

- Communication with Fellows in the field is a persistent challenge due to poor connectivity. Scheduling adequate face-face mentoring time during workshops is important to ensure Fellows thoroughly understand how to apply technical knowledge and skills during their field projects.

National Government initiative to strengthen the public health workforce and health systems across all levels of government. The Papua New Guinea (PNG) National Department of Health (NDOH) designed FETPNG to equip health practitioners with the knowledge, skills and confidence to implement data collection, analysis and interpretation, disease surveillance and outbreak response. Alongside these traditional field epidemiology competencies, FETPNG also includes an operational research component where Fellows design, implement and evaluate an intervention project to address pressing local 
public health issues. It is one of the few field epidemiology training programmes in the world to include evidence-based intervention projects as a focus of the Fellows training. Institutionally, FETPNG addresses key objectives in the PNG Development Strategic Plan 20102030, ${ }^{1}$ the Health Strategic Plan 2011-2020, ${ }^{2}$ and the Asia Pacific Strategy for Emerging Diseases and Public Health Emergencies. ${ }^{3}$

\section{LOCAL SETTING}

The Independent State of PNG has 8.2 million inhabitants, an annual population growth rate of $2.8 \%$ and the world's most rural $(87.5 \%)$ population. ${ }^{4}$ It is the most ethnically and linguistically diverse country in the world, with over 1000 ethnic groups and 850 indigenous languages. ${ }^{5}$ PNG ranks 153 rd out of 189 countries in the Human Development Index. ${ }^{6}$ Healthcare service delivery is complicated by resource constraints and logistical challenges due to the country's diverse geography, including its 600 Islands, lowland forests, extensive marshes, dry savannahs and mountainous terrain. PNG has a critical shortage of human resources to provide healthcare, with a skilled health worker density of 5.87 per 10000 population, far lower than the average of 65.34 per 10000 population for the Western Pacific as a whole. ${ }^{47}$ Existing syndromic surveillance has limited coverage and sensitivity and there has been limited capacity to respond to outbreaks and other public health threats.

\section{APPROACH}

In 2012, a meeting was held by the NDOH, WHO and US Centers for Disease Control and Prevention (CDC) to address the shortage of epidemiological capacity in the health service. The recommendations of the meeting were presented to leadership at the $\mathrm{NDOH}$ and WHO Country Office, followed by a summit to reach consensus on the structure of the training programme and specific programme goals. Consequently, a field epidemiology training plan developed whereby:

- The NDOH would house and administer the programme.

- The programme would be practically oriented with the aim of providing tangible, meaningful benefits.

- Fellows from provincial and district health offices would be prioritised.

- An 8-month curriculum was to be preferred over a traditional 2-year programme in order to rapidly address capacity needs.

- Fellows would remain in their jobs during training.

After discussion with partners and stakeholders, consensus was reached to launch a field epidemiology training programme with a novel curriculum that included traditional field epidemiology topics (table 1) and a public health intervention project coupled with monitoring and evaluation. Two ambitious targets were established: to have at least one field epidemiologist in each of the 22 provinces within 5 years, and one in each of the 89 districts within 10 years. FETPNG commenced in April 2013.

Table 1 Field epidemiology training programme of Papua New Guinea core competencies

\begin{tabular}{|c|c|}
\hline Competency & Description \\
\hline $\begin{array}{l}\text { Descriptive analysis of health data to support } \\
\text { outbreak detection and response, and } \\
\text { intervention-based research }\end{array}$ & $\begin{array}{l}\text { Analyse health data using basic principles of descriptive epidemiology (eg, } \\
\text { clinical, time, place, person) } \\
\text { Calculate rates and descriptive statistics } \\
\text { Create tables, graphs, maps } \\
\text { Identify trends, patterns and unusual deviations }\end{array}$ \\
\hline Monitor and assess local surveillance data & $\begin{array}{l}\text { Describe the role of indicator and event-based surveillance in public health } \\
\text { practice } \\
\text { Describe the key characteristics of surveillance: purpose, list of diseases } \\
\text { included, flow, case definitions, timeliness requirements and so on } \\
\text { Describe how to screen, detect and verify events of public health importance } \\
\text { Evaluate a surveillance system }\end{array}$ \\
\hline Investigate disease outbreaks & $\begin{array}{l}\text { Understand the steps in an outbreak investigation, including identifying } \\
\text { appropriate control measures in different scenarios }\end{array}$ \\
\hline $\begin{array}{l}\text { Conduct field research leading to a practical } \\
\text { intervention that is implemented, monitored } \\
\text { and evaluated }\end{array}$ & $\begin{array}{l}\text { Conduct an applied research project that collects data or utilises existing } \\
\text { data to identify gaps or barriers to the delivery of a health programme or } \\
\text { service } \\
\text { Design and implement an evidence-based intervention to improve health } \\
\text { programme delivery }\end{array}$ \\
\hline $\begin{array}{l}\text { Communicate effectively with colleagues and } \\
\text { community }\end{array}$ & $\begin{array}{l}\text { Prepare and deliver an oral presentation for health facility management and } \\
\text { staff, and for NDOH senior management } \\
\text { Prepare abstracts, manuscripts or presentations for scientific audiences (eg, } \\
\text { conferences, peer-reviewed publications) }\end{array}$ \\
\hline
\end{tabular}

$\mathrm{NDOH}$, National Department of Health. 


\begin{tabular}{|c|c|c|c|c|}
\hline Workshop 1 & Field project & Workshop 2 & Intervention & Workshop 3 \\
\hline $\begin{array}{l}\text { - Intro to epidemiology } \\
\text { - Intro to surveillance } \\
\text { - Descriptive epidemiology } \\
\text { - Excel skills-level } 1 \\
\text { - Research methods } \\
\text { - Questionnaire design } \\
\text { - Surveillance evaluation } \\
\text { - Outbreak investigation } \\
\text { - Descriptive analysis } \\
\text { - Role of laboratory } \\
\text { - Scientific communications } \\
\text { - Field project development } \\
\text { - One-on-one mentoring }\end{array}$ & $\begin{array}{l}\text { - Finalise and pilot data } \\
\text { collection instrument } \\
\text { - Collect or extract local } \\
\text { health data } \\
\text { - Analyse and review data } \\
\text { - Identify problem } \\
\text { - Understand underlying } \\
\text { reasons behind problem } \\
\text { (barriers, enablers, etc.) } \\
\text { - Ongoing remote } \\
\text { engagement with mentor } \\
\text { - Outbreak investigation-if } \\
\text { opportunity presents }\end{array}$ & $\begin{array}{l}\text { - Intro to public health } \\
\text { interventions } \\
\text { - Presentation of results } \\
\text { from field projects } \\
\text { - Excel skills - level } 2 \\
\text { - Data analysis and statistics } \\
\text { - level } 1 \\
\text { - Monitoring and evaluation } \\
\text { of public health } \\
\text { interventions } \\
\text { - Scientific presentation } \\
\text { - skills } \\
\text { - Intervention development } \\
\text { One-on-one mentoring }\end{array}$ & $\begin{array}{l}\text { - Implementation of } \\
\text { intervention } \\
\text { - Monitoring of } \\
\text { intervention } \\
\text { - Evaluation of } \\
\text { intervention } \\
\text { - Ongoing remote } \\
\text { - engagement with mentor } \\
\text { Outbreak investigation - } \\
\text { if opportunity presents) }\end{array}$ & $\begin{array}{l}\text { - Review of epi concepts } \\
\text { - } \text { statistics - level } 2 \\
\text { - Introduction to Rapid } \\
\text { Response Teams } \\
\text { - Opportunities for further } \\
\text { training } \\
\text { - Opportunities to present } \\
\text { or publish } \\
\text { - Final project \& } \\
\text { intervention } \\
\text { presentation } \\
\text { - Graduation ceremony }\end{array}$ \\
\hline $\begin{array}{c}2 \text { weeks } \\
\text { April }\end{array}$ & $\begin{array}{l}\sim 4 \text { months } \\
\text { April-August }\end{array}$ & $\begin{array}{l}1 \text { week } \\
\text { August }\end{array}$ & $\begin{array}{l}\sim 3 \text { months } \\
\text { August-November }\end{array}$ & $\begin{array}{l}1 \text { week } \\
\text { November }\end{array}$ \\
\hline
\end{tabular}

The FETPNG is administered and governed by the $\mathrm{NDOH}$, with overall strategic direction provided by the Senior Executive Management, particularly through the Executive Manager for Public Health. The programme is funded by the WHO PNG Country Office and the NDOH.

The programme consists of five training phases (figure 1) over 8 months. Each cohort consists of 15-18 health workers (Fellows) supported by a team of trainers and mentors (faculty). The faculty includes epidemiologists, public health managers and public health physicians from the NDOH, Provincial Health Authorities, WHO, US CDC, and Hunter New England Health (a district health unit in Australia with long-standing ties to the Pacific region). Applications for Fellows are solicited from national and provincial health managers, and accepted directly from applicants, then vetted and selected by the NDOH faculty. Selection is based on geographic representation, gender and current role (with priority given to district level health workers). Fellows participate in classroom training (workshops) and spend approximately $10 \%$ of their time working on FETPNG field-based epidemiology and intervention projects in their usual workplace. While FETPNG concentrates on communicable diseases, Fellows can select field projects related to a range of public health priorities, including non-communicable diseases, maternal health, reproductive health and gender-based violence. These projects are developed in close consultation with their mentors.

Note there has been slight variation in curriculum each year in order to address timely health issues such as preparedness for Ebola, response to El Niño, and response to vaccine derived poliovirus 1 .

The curriculum is focused on developing competencies that are retained, applied and lead to measurable impacts. Skills learnt in workshop 1 are applied during epidemiological field projects where Fellows explore a public health problem. During workshop 2, Fellows design a public health intervention to address this problem. An evidence-based intervention is implemented, monitored and evaluated during the second fieldwork phase (see table 2 for intervention project examples). During each workshop, Fellows present their epidemiological and intervention project plans and results to other Fellows and faculty for discussion and critique. Programme managers and senior executives from $\mathrm{NDOH}$ and $\mathrm{WHO}$ also attend these presentations. Graduates of the programme are encouraged and supported to present their findings to workplace managers and at national and international conferences. They are also encouraged to publish their findings.

Mentoring of Fellows in the classroom and (remotely) in the field is a key element of FETPNG. The mentor to Fellow ratio is maintained at 1:2 to 1:3. Mentors complete training on mentoring before taking on this responsibility. From the outset, FETPNG adopted a strategy of progressively equipping and empowering local faculty to take leading training and mentoring roles. In 2018, the six local faculty (PNG nationals from NDOH and Provincial Health Authorities) led the majority of the training and mentoring. Half of the local faculty are graduates of FETPNG. Mentoring of mentors, pairing of local and international mentors, and training-of-trainer initiatives further facilitate local leadership.

\section{RELEVANT CHANGES}

From 2013 to 2018, a total of 81 Fellows graduated from FETPNG, including two Fellows from Solomon Islands. All Fellows remained in their jobs during training. The overall proportion of females graduating was $43 \%$ 
Table 2 Examples of public health interventions implemented by FETPNG fellows, 2013-2018

HIV HIV screening of mothers visiting antenatal care increased from $75 \%$ to $99 \%$ and treatment coverage for HIV-positive mothers from $76 \%$ to $100 \%$ (Western Highlands Province) through advocacy and improving linkages to care and treatment. A total of 364 women were on treatment by the end of the training

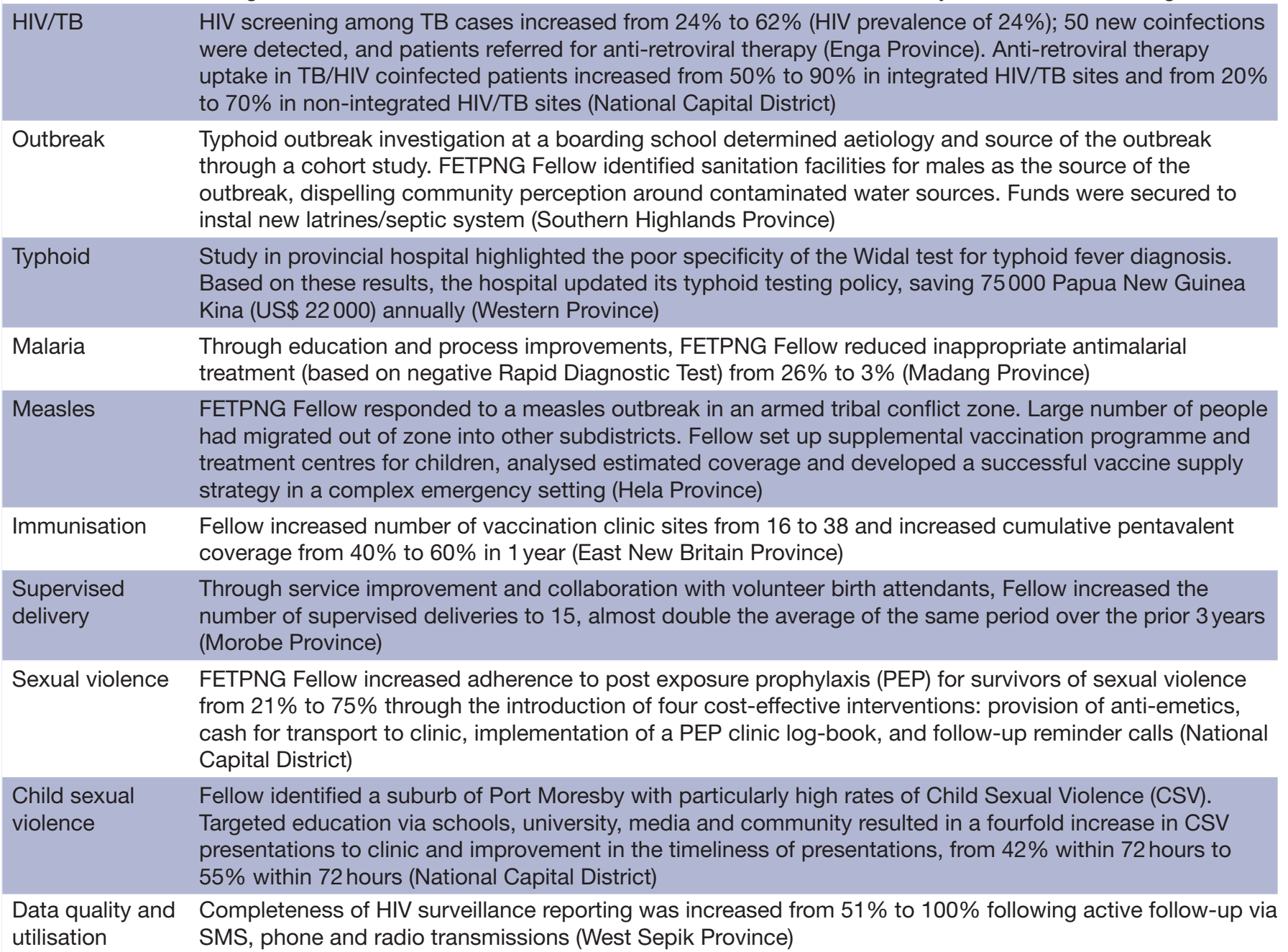

FETPNG, field epidemiology training programme of Papua New Guinea; TB, tuberculosis.

$(n=35)$, ranging from $25 \%$ in 2013 to $60 \%$ in 2016. At least one FETPNG Fellow has graduated from every PNG province, as well as the Autonomous Region of Bougainville and the National Capital District. This target was met in 2016, 1 year ahead of the 5-year target. Currently there are graduates in 43 of PNG's 89 districts (48\%), with eight districts having more than one graduate. Of the 81 Fellows graduating from 2013 to $2018,84 \%(n=68)$ were drawn from provincial or district health departments or organisations, with $14 \%(n=11)$ from the national level and $2 \%(n=2)$ from outside of PNG.

The majority $(80 \%, n=65)$ of Fellows work as Health Extension Officers (medical practitioners roughly equivalent to advanced practice nurses) when enrolled in FETPNG. Of the Health Extension Officers, most were employed in clinical $(48 \%, \mathrm{n}=31)$ or management roles $(22 \%, \mathrm{n}=14)$. There have also been Surveillance Officers $(7 \%, \mathrm{n}=6)$ (including one from the animal health sector), Nursing Officers $(6 \%, \mathrm{n}=5)$, Environmental
Health Officers $(4 \%, \mathrm{n}=3)$ and Medical Officers $(2 \%$, $\mathrm{n}=2$ ) enrolled in the programme. While the focus of FETPNG has been on training public health staff within PNG's public service $(93 \%, \mathrm{n}=75)$, Fellows from nongovernmental organisations $(4 \%, \mathrm{n}=3)$ and universities $(1 \%, \mathrm{n}=1)$ have also been trained. Most $(73 \%, \mathrm{n}=59)$ Fellows focused on communicable disease projects during their training with the remaining working on non-communicable disease priorities $(20 \%, \mathrm{n}=16)$ or surveillance evaluations $(7 \%, \mathrm{n}=6)$. Nine Fellows $(11 \%)$, representing all levels of the public health system, led investigations of disease outbreaks during their training.

The most common focus area for intervention projects was tuberculosis (TB), including multidrug resistant TB (MDR-TB) $(15 \%, \mathrm{n}=12)$, followed by immunisation $(11 \%, \mathrm{n}=9)$, TB/HIV coinfection $(7 \%, \mathrm{n}=6)$, reproductive health $(7 \%, \mathrm{n}=6)$ and sexually transmitted infections (STI/HIV) $(6 \%, \mathrm{n}=5)$. The outbreak investigations led by fellows included: measles $(n=2)$, typhoid $(n=2)$, and 
single outbreaks of cholera, haemorrhagic fever, chikungunya, dengue, and foodborne illness. In 2018, $96 \%$ $(n=78)$ of all FETPNG graduates and current Fellows were involved in supporting the response to an outbreak of vaccine-derived polio virus 1 (cVDPV1) in PNG, with several playing lead roles in Provincial Emergency Operations Centres.

Following graduation, 21 (26\%) Fellows have presented their work at international conferences; including global or regional Training Programs in Epidemiology and Public Health Interventions Network (TEPHINET) meetings. Two Fellows have published their field projects in academic journals. ${ }^{89}$ FETPNG has also provided a platform for graduates to pursue further advanced training, including at the Masters level. Many of the Fellows' intervention projects have resulted in positive changes to health systems and services (table 2).

\section{LESSONS LEARNT}

Field epidemiology training programmes throughout the world are based on a variety of administrative models. Most are housed within Ministries of Health, with the majority of the remainder housed in academic institutions. While there may be some benefits to housing FETPs in academic institutions, it has always been the consensus of faculty that FETPNG be embedded within the NDOH in order to ensure Fellow and graduate involvement in real-time surveillance, response activities and public health interventions of national importance. The strong support from the NDOH in the design, delivery and advocacy of the programme and the utilisation of data and recommendations generated by Fellows are key elements in the success and sustainability of FETPNG.

Senior staff within NDOH provided clear direction and leadership during the early planning phases and throughout implementation of the programme. WHO and CDC technical experts supported the direction provided by the NDOH and lent expertise in curriculum development. While there are standard FETP curricula available for frontline, intermediate and advanced programmes, ${ }^{10-12}$ the decision to create a programme tailored to the needs and capacity of PNG appears central to the programme's success. The flexibility to readily update the curriculum has permitted a dynamic and responsive programme that has continually sought to maximise training impact and respond to national public health priorities. Such curriculum responsiveness would be considerably restricted if the programme were to be housed within an academic institution.

Continual adjustments to the FETPNG curriculum have been made in response to feedback from Fellows and faculty. Based on this feedback, more time has now been allocated to teaching practical skills, such as use of Microsoft Excel, and less time on higher-level statistical analysis. New teaching styles have also been incorporated into the curriculum resulting in a decrease in didactic lectures and an increase in case studies that are based on real PNG events, role plays, panel discussions and small group activities.

From 2013 to 2018, FETPNG Fellows were primarily health professionals working at the Local (Health Centres), District, Provincial or National levels of government. Fellows remained in their substantive position while completing the FETPNG. This workplace-based model is cost effective and allows Fellows to improve health systems and programme delivery in their workplace while undertaking training. This training strategy empowers Fellows to take ownership of local health challenges and act on the data they collect and analyse.

As of November 2019, 98.7\% of all graduates who were working in the public health service of PNG when enrolled in FETPNG, continue to work in PNG's public health service. Several have subsequently been promoted, including to senior technical and executive leadership positions. Retention of graduates within the government system is a key outcome that supports the long-term objectives of strengthening health systems and developing a network of response-ready public health professionals across the country. High level government recognition of the value of FETPNG and the practical outcomes of field projects have contributed to the retention and promotion of Fellows within the government system.

The decision to make public health interventions a requirement of the programme has become a defining characteristic of FETPNG. The faculty strongly feel that Fellows must be equipped with the skills and provided the opportunity to address urgent public health priorities during their training. While the public health impacts of FETPNG intervention projects have been encouraging, they are often limited in scope in order to be completed during the training, and are not always sustained following graduation. Further work is needed to explore ways to ensure successful interventions are continued and scaled up. One of the strategies adopted to address this limitation was the implementation of an advanced FETPNG (aFETPNG) programme in 2019. This advanced programme (18 months) is designed to focus the Fellows' epidemiological and intervention projects on key national priorities in order to develop a strong evidence base for driving national level policy and programme changes. Greater engagement of policy makers and programme directors at Provincial and National levels is be a key part of the advanced programme. The aFETPNG Fellows work in teams, rather than individually, to address key priority areas identified during stakeholder engagement and prioritisation workshops. aFETPNG will culminate in the production of policy briefs and a stakeholder symposium, both geared towards scaling and sustaining successful interventions. In addition to the aFETPNG, the faculty are exploring links with government and nongovernment partners to provide FETPNG graduates with ongoing opportunities to apply field epidemiology and operational research skills. Finally, a mixed-methods evaluation is underway to understand the impact of FETPNG training as well as barriers and enablers to translating 
knowledge into action. The results from this evaluation will be used to further enhance the impact of FETPNG.

Communication between mentors and Fellows during field work phases has been an ongoing challenge due to poor phone and internet connectivity. As a result, priority is given to one-on-one mentoring during the classroom teaching modules. This one-on-one time allows mentors to build rapport with their Fellow and tailor support specific to the Fellow's needs prior to them leaving for the field. Mentors and Fellows agree on communication expectations during the field work phases. WhatsApp and a private FETPNG Facebook group also support communication between Fellows, alumni and mentors. Recently, the programme has hired a project officer who will, among other things, help coordinate follow-up of Fellows in the field. NDOH and WHO staff will also take opportunities to visit Fellows while on duty travel.

One of the 10-year FETPNG targets established by $\mathrm{NDOH}$ was to have at least one trained field epidemiologist in each of PNG's 89 health districts. To date, 43/89 districts have an FETPNG graduate. Given this focus, only a limited number of training spaces have been allocated to Fellows from non-governmental or non-health related organisations. Once the District target is met, it is likely that additional candidates from Agriculture, Environment and non-government sectors will be enrolled in FETPNG. While the majority of Fellows have chosen communicable disease related projects, an increasing number have selected non-communicable disease topics. As the project areas diversified, the faculty has expanded to include an expert in reproductive health. It is likely that additional faculty with experience in non-communicable diseases will be required to support the programme into the future. The faculty are also looking to enhance the engagement of Fellows with technical experts from $\mathrm{NDOH}, \mathrm{WHO}$ and non-governmental organisations in PNG.

Over the next 2 years the local PNG faculty will continue to take on increasing leadership responsibilities for the implementation of FETPNG. To support this transition, additional training for faculty is planned. Local faculty will continue to be deployed in outbreak response activities and will begin to lead Provincial rapid response teams. The NDOH is planning to further strengthen its local leadership capacity by hiring a full time FETPNG coordinator in the near future. These activities will ensure that FETPNG is sustained and remains owned and lead by NDOH. The local faculty are also planning to formalise the alumni network through the establishment of an FETPNG association in PNG.

\section{CONCLUSION}

In the first 6 years of the FETPNG, the programme graduated 81 field epidemiologists who completed projects that contributed to improvements in public health practice in PNG. The Fellows comprise a nation-wide network that continues to be used for local and national outbreak response activities, surveillance strengthening projects, and operational research to improve health systems and services in their workplaces. The ownership of FETPNG by the NDOH and the focus on interventions are key contributors to the success of the programme. The progressive transition of leadership to local PNG faculty and the prioritisation of mentoring throughout the training are also essential components of FETPNG. The faculty continue to explore ways to further enhance the impact of this workplace training programme, including through impact evaluation activities and an advanced training programme. The training and field projects of FETPNG have directly saved lives, strengthened health systems, enhanced surveillance and facilitated the investigation of disease outbreaks. These tangible outcomes are a source of pride among Fellows and faculty and prove to each Fellow that they are equipped and able to address important health challenges and make a measurable difference in their workplaces and communities.

\section{Author affiliations}

${ }^{1}$ Government of Papua New Guinea National Department of Health, Port Moresby, National Capital District, Papua New Guinea

${ }^{2}$ Health Protection, Hunter New England Health, Wallsend, New South Wales, Australia

${ }^{3}$ Center for Global Health, Centers for Disease Control and Prevention, Atlanta, Georgia, USA

${ }^{4}$ World Health Organization Health Emergencies Programme, World Health Organization, Geneva, Switzerland

${ }^{5}$ Public Health Department, West New Britain Provincial Health Authority, Kimbe, Papua New Guinea

${ }^{6}$ Department of Health, Autonomous Bougainville Government, Buka Town, Papua New Guinea

Contributors BR and JF contributed equally to this paper as colead authors. They developed the overview of the paper, compiled the data from existing records, analysed the data and prepared the manuscript with input from all authors. MO'R, BIP, RD, BP, MB, AP, TM, ST-P, AY, DP, JC, DND, AH, SB all provided substantial contribution into the conception of the paper, interpretation of the data and critical review of the manuscript.

Funding The authors have not declared a specific grant for this research from any funding agency in the public, commercial or not-for-profit sectors.

Competing interests None declared.

Patient consent for publication Not required.

Provenance and peer review Not commissioned; externally peer reviewed. Data availability statement Data are available upon reasonable request

Open access This is an open access article distributed in accordance with the Creative Commons Attribution Non Commercial (CC BY-NC 4.0) license, which permits others to distribute, remix, adapt, build upon this work non-commercially, and license their derivative works on different terms, provided the original work is properly cited, appropriate credit is given, any changes made indicated, and the use is non-commercial. See: http://creativecommons.org/licenses/by-nc/4.0/.

ORCID iD

James Flint http://orcid.org/0000-0002-5525-1785

\section{REFERENCES}

1 Department of National Planning and Monitoring. Papua New Guinea development strategic plan, 2010-2030: department of national planning and monitoring, PNG 2010.

2 Government of Papua New Guinea. National health plan 2011-2020: strategic policy division of the National department of health 2010. 
3 World Health Organization. Regional office for the Western Pacific. Asia Pacific strategy for emerging diseases and public health emergencies (APSED III): advancing implementation of the International health regulations (2005): working together towards health security. Manila 2017.

4 World Health Organization. Regional office for the Western Pacific. Papua new Guinea-WHO country cooperation strategy 2016-2020. Manila 2016.

5 Reilly B. Ethnic conflict in Papua New Guinea. Asia Pac Viewp 2008;49:12-22.

6 Human Development Reports [Internet], 2018. Available: http://hdr undp.org/en/countries/profiles/PNG [Accessed 15 Jul 2019].

7 Global health Observatory data Repository. Skilled health personnel Data by WHO Region [Internet], 2018. Available: https://apps.who. int/gho/data/view.main.HWF10WHOREGv?lang=en [Accessed 12 Nov 2019]
8 Morisause M, Flint J. Identifying barriers to accessing family planning contraceptives among women aged 15-49 years in Maprik district, East Sepik Province, Papua New Guinea, 2014. Pacific J Reproduct Health 2017;1:232-9.

9 Kamac K, Paterson B, Flint J. Lessons learnt from a measles outbreak in Madang Province, Papua New Guinea, June 2014 March 2015. Western Pacific Surveil Respon J 2017;8:1-5.

10 Traicoff DA, Walke HT, Jones DS, et al. Replicating success: developing a standard FETP curriculum. Public Health Rep 2008;123:28-34.

11 López A, Cáceres VM. Central America field epidemiology training program (Ca FETP): a pathway to sustainable public health capacity development. Hum Resour Health 2008;6:27.

12 André AM, Lopez A, Perkins S, et al. Frontline field epidemiology training programs as a strategy to improve disease surveillance and response. Emerg Infect Dis 2017;23. 